\title{
INFLUENCE OF IN-PLANE DEFORMATION IN HIGHER ORDER BEAM THEORIES
}

\author{
SAPOUNTZAKIS Evangelos ${ }^{1}$, ARGYRIDI Amalia ${ }^{2}$ \\ ${ }^{l}$ Institute of Structural Analysis and Antiseismic Research, School of Civil Engineering, National Technical \\ University of Athens, Athens, 15780, Greece, cvsapoun@central.ntua.gr \\ ${ }^{2}$ Institute of Structural Analysis and Antiseismic Research, School of Civil Engineering, National Technical \\ University of Athens, Athens, 15780, Greece, a.argyridi@gmail.com
}

\begin{abstract}
Comparing Euler-Bernoulli or Tismoshenko beam theory to higher order beam theories, an essential difference can be depicted: the additional degrees of freedom accounting for out-of plane (warping) and in-plane (distortional) phenomena leading to the appearance of respective higher order geometric constants. In this paper, after briefly overviewing literature of the major beam theories taking account warping and distortional deformation, the influence of distortion in the response of beams evaluated by higher order beam theories is examined via a numerical example of buckling drawn from the literature.
\end{abstract}

KEYWORDS: Beam theories, Distortion, In-plane deformation, Warping, Out-of-plane deformation, Buckling

\section{Introduction}

In engineering practice, Euler - Bernoulli and Timoshenko (classical) beam theories are frequently used for the analysis of slender members in cases of negligible or not shear deformations, respectively. This is owed to the fact that beam theories have numerous inherent advantages over more refined approaches ( $3 \mathrm{~d}$ solid, shell models) which summarize to the following:

- less modelling time

- isolation of structural phenomena and results interpretation (rotations, warping parameters, stress resultants etc. are also evaluated in addition to displacements and stress components)

- easier modelling of supports and application of external loading

- significantly less number of degrees of freedom (dofs) - less computational time

- parametric analyses without the construction of multiple models

Despite the fact that classical beam theories are really popular due to the aforementioned reasons, they do not suffice when it comes to cases where intense out-of plane (warping) (e.g. [1]) or in-plane (distortional) (e.g. [2]) deformations take place. The reason is the assumption of rigid cross-section that makes them unable to take into account warping and distortion. In order to overcome this difficulty higher order beam theories have been developed maintaining the advantages of classical beam theories and being able to simulate problems with significant warping or distortional deformations.

A well-known phenomenon associated with non-uniform shear warping is shear lag which usually occurs in folded or box-shaped beams. It has received a lot of attention from plethora of researchers who have studied it some decades ago. For example, Reissner [3] employed 
energy method approach, Malcolm and Redwood [4] and Moffatt and Dowling [5] used finite elements [6] to study shear lag. In contemporary regulations, the importance of shear lag is acknowledged. More specifically, in section 2 of EC3-part 1.5 [7], shear lag is taken into account by means of the effective breadth. According to this method, the effects of shear lag of flanges in global analysis may be taken into account using an effective breadth which can be considered as uniform over the length of the span. Although this method is simple, it leads to an identical effect of shear lag in every point along the beam independently of the shear flow at a specific cross-section. In addition, instructions on how the effects due to shear lag should be considered at serviceability and fatigue limit state are provided in Section 3 of EC3-part 1.5 [7]. The equations for the evaluation of effective breadth under elastic and inelastic conditions are also provided. According to section 5.4 of EC4 [8]-[9] shear lag has also to be taken into account in composite steel and concrete structures. However, the cases where shear lag affects significantly the global analysis are not specified by the relevant guidelines. In contrast to EC2 and EC3, European regulations regarding concrete structures (EC2 [10]) do not examine the effect of shear lag. All the above, lead to the conclusion that recommendations on shear lag effects in beams are based on a simplifying approach which may fail to capture satisfactorily the actual structural behavior of the member, since the influence of shear lag phenomenon is not constant along the beam length, while apart from the geometrical configuration of the crosssection it depends also on the type of loading [11].

As far as distortional effects in stress and strain distribution of beam members are concerned, their significance is also highlighted in up-to-date regulations. However, in most cases the guidelines are general without providing specific modelling instructions in order to take into account the aforementioned effects. In EC3-Part 1.1 [7], for instance, the most of regulations regarding torsion are valid only when distortional deformation can be neglected (section 6.2.7). In addition, when it comes to buckling resistance of members (section 6.3.3) the guidelines are effective when distortional deformations are absent from the cross-section. The significance of distortion is additionally highlighted in section 6.3.5.2 where it is stated that it has to be prevented at the plastic hinge location. Distortional effect should be also taken into account during the evaluation of nominal stresses from fatigue actions (EC3, Part 1.9, Section 4 [7]) and the design of unreinforced joints (Part 1.8 Section 7.5.2.1(7)). As far as design of aluminum structures susceptible to fatigue is concerned, according to Eurocodes it is stated that modified nominal stresses should be used in place of nominal stresses (EC9 Part 1.3 Section 5.2 [12]). Finally, not only does distortion happen in steel and aluminum structures but it also occurs in concrete structures. For example, the opening of a joint in a box under certain specifications (EC2-Part 2-Section 6.3.2(106) [10]) may change the torsional resisting mechanism from Bredt circulatory torsion to a combination of warping torsion and St. Venant torsion. As a result, the web shear due to torsion is practically doubled and significant distortion of the section takes place.

The regulations of steel and composite bridges pay more attention to distortional phenomenon. Particularly, in Part 2 of EC3 [7] it is clearly stated that for members under torsion, both torsional and distortional effects have to be dealt (6.2.7.1(1)). However, it is mentioned that the aforementioned effects may be neglected in members where due to crosssectional transverse bending stiffness and/or diaphragm action, the effects from distortion do not exceed $10 \%$ of bending effects. Similarly, attention to distortion matters is given in other guidelines as well such as those by American Association of State Highway and Transportation Officials (AASHTO) and Hanshin Expressway Public Corporation of Japan. According to these the maximum spacing of diaphragms placed in curved girder bridges is controlled so as to minimize distortional warping normal stresses in terms of bending normal ones (less than $10 \%$ for AASHTO, less than 5\% for Hanshin Expressway Public Corporation of Japan) [13]. 


\section{Higher order beam theories considering warping and distortion}

A lot of research efforts have been published concerning the development of higher order beam theories, including distortional effects, the past years. The majority of these researches deal with thin-walled profiles; hence, the simplifying assumptions of Thin Tube Theory TTT [14] dominate in the formulation of such theories. Adopting the concept of TTT, some of the first classical approaches examine the torsional distortion problem by reducing it to an equivalent Beam-on-Elastic-Foundation (BEF) one [14]-[16]. This approach clarifies some significant factors concerning the mechanism of distortion. Confirming BEF analogy, numerous research efforts extended classical Vlasov TTT by formulating corresponding fourthorder differential equations taking into account torsional distortion, introducing at the same time basic notions such as that of distortional warping, distortional center and distortional moment [13], [17]-[23]. The connection of the above mentioned additional distortional warping with secondary torsional shear stresses has been also highlighted [24]. However, the previous studies which focus mainly on box-shaped bridge decks and are not general, because they do not include flexural distortional effects, while restrictions are set with respect to cross-sectional shape and its deformation (e.g. in-plane shear deformation of plate element of the beam due to distortion is ignored).

GBT (Generalized Beam Theory), formulated by Schardt [2], [25], played an important role in generalizing Vlasov's theory by integrating flexural and torsional distortional effects. In what followed, Davies and co-researchers [27]-[30] disseminated GBT through a series of publications studying linear static or bucking problems of thin-walled beams. These first GBT formulations are based on the hypothesis that the structural member has an open-shaped (initially un-branched) cross-section consisting of thin rectangular walls/plates; thus thin plate theory assumptions are employed for each wall. GBT analysis consists of two phases of analysis, namely a cross-sectional analysis and a member analysis. Cross-sectional analysis is then based on two stages comprising the establishment of warping modes and the subsequent establishment of distortional ones by using Vlasov's zero-shear stress condition. This method becomes more complicated in branched cross-sections (i.e. in cross sections where a node may connect more than two plate elements) and in closed-shaped ones where zero-shear stress condition cannot be applied. Camotim, Silvestre and co-researchers have systematically proposed solutions to face the aforementioned inherent downsides of the method. They expanded it to able to study a variety of cross-sections, orthotropic materials, geometrically nonlinear and inelastic problems [31]-[41]. The general modal-decomposition-type character of its cross-sectional analysis consists an important advantage of GBT. This characteristic facilitated the categorization of in-plane modes to global, distortional or local ones. This categorization makes easy the comprehension of structural mechanisms and their hierarchical classification, confirming an inherent advantage of beam theories over more elaborate yet more complicated methods (e.g. 3d solid, shell models).

Discretization of the cross-section determines the number and the accuracy of in-plane deformation modes evaluated by GBT cross-sectional analysis. The cross-sectional shape and nodal topology affect this discretization constituting it an undoubtedly complicated task (openshaped branched or un-branched, closed-shaped branched or un-branched cross-sections may be involved). Other researchers have developed TTT introducing the eigenvalue-type crosssectional analysis [42]-[43] establishing deformation modes and permitting their sorting in order of significance. Ranzi and Luongo [44], Jönsson and Andreassen [45]-[48] and Vieira et al. [49] have employed eigenvalue cross-sectional analysis highlighting the fact that with this approach it is not necessary to classify cross-sections according to their geometrical configuration (open-, close-shaped, branched or un-branched). Additionally, the resulting 
modes contain the most significant ones and form a more meaningful and insightful basis of functions as compared to GBT ones which exhibit a more local character [44].

It is worth mentioning that simultaneously with GBT, Finite Strip Method (FSM) has been also widely employed for the analysis of slender thin-walled structural members. Analogously with GBT, FSM is based on plate theory assumptions which are applied on each wall of the cross-section. FSM couldn't be classified as beam theory but as a general purpose FEM-based method. However, studies exploiting the advantages of FSM in combination with GBT in order to study buckling problems of beams have been presented by Schafer, Ádány and coresearchers. For this purpose, kinematical and strain constraints have been applied to conventional FSM leading the development of the so-called constrained FSM (cFSM) [50], [51]-[56]. cFSM employs specially selected constraints which enforce the member to deform according to mechanical constraints that match definitions of global or distortional buckling classes [55].

It is worth noting that, all the above literature incorporates distortional effects in beam analysis by means of TTT. Even though TTT offers a simpler formulation, it restricts the range of application of relevant models, while it has been observed that its accuracy is questionable even in cases of cross-sections that are classified as thin-walled [57]. The problem of distortional analysis of beams of arbitrary cross-section, exhibits increased complexity even though the basic analysis stages are the same with GBT ones. Regarding sectional analysis, a suitable basis of out-of-plane deformation modes (warpings) accompanied by corresponding in-plane ones (distortions) has to be established as well; however this task exhibits far more complex behavior, since in the case of arbitrary cross section, kinematical considerations and constitutive relations cannot be simplified. In contrast, the member analysis is similar to those of GBT, since the formulation comprises the expression of displacement field as a linear combination of the obtained modes multiplied by relevant parameters which can be perceived as generalized coordinates. More specifically, the differences with TTT/GBT concern the handling of shear deformation by using of dependent or independent parameters as generalized coordinates.

St. Venant problem of prismatic elastic bodies plays a crucial role for the establishment of exploitable warping/distortional functions towards solving the problem for arbitrarily shaped homogeneous or composite cross-sections. In these problems the analysis of deformation reduces to the evaluation of 2-D functions over the cross-sectional domain often referred to as central solutions (e.g. see the studies of Kosmatka and Dong [58] and Ie and Kosmatka [59] for St. Venant solutions in anisotropic prismatic bodies). In St. Venant problems, the central solution is valid along the examined prismatic body provided that warping/in-plane deformations of the root cross-section are not restrained (rigid body movements are though prohibited). Nevertheless, central solution is usually applied in more general boundary conditions as suggested by Saint-Venant through the "principle of elastic equivalence of statically equipollent systems of load" [60]-[62]. This statement establishes the so-called St. Venant's Principle according to which the possible restraint near the support of the examined prismatic body does not affect the solution away from the support. However, towards expanding St. Venant's theory, various researchers investigate the so-called end-effects (also referred to as extremity solutions, eigensolutions or transitional solutions [63]) when the above assumption is not maintained (e.g. in case of a clamped beam end). Hence, employing the semi-inverse method of St. Venant under static conditions, a displacement field of the following form can be assumed [62] 


$$
\begin{gathered}
\underset{\text { Total displacements }}{\overline{\mathbf{u}}}=\underset{\text { St. Venant solution }}{\overline{\mathbf{u}}_{S V}}+\underset{\begin{array}{c}
\text { residual displacements } \\
\text { based on end-effects }
\end{array}}{\overline{\mathbf{u}}_{\text {res }}} \\
\overline{\mathbf{u}}_{\text {res }}(x, y, z)=\sum_{i=1}^{K} a_{i}(x) \mathbf{W}_{i}(y, z)=\sum_{i=1}^{K} a_{i}(x)\left\{\begin{array}{c}
\Phi_{i}(y, z) \\
V_{i}(y, z) \\
W_{i}(y, z)
\end{array}\right\}
\end{gathered}
$$

According to the above equations, the displacement vector $\overline{\mathbf{u}}$ of an arbitrary point of the cross-section is obtained as the sum of St. Venant solution vector $\overline{\mathbf{u}}_{S V}$ (e.g. see Kosmatka and Dong [58]) combined with a residual displacement vector $\overline{\mathbf{u}}_{r e s}$ due to end-effects which are responsible for the generation of self-equilibrating stress distributions [61]-[62], [64]-[65]. These additional displacements are written as a sum of $K$ two-dimensional functions $\mathbf{W}_{i}$ (warping/in-plane deformation functions) multiplied by parameters $a_{i}$ expressing their longitudinal intensity. Stress components due to end-effects are considered to independently satisfy the equations of local equilibrium. Thus, applying the three-dimensional elasticity equilibrium equations, exploiting the exponentially decaying character of these end-effects and introducing a proper discretization scheme of the cross-section, a 2-D quadratic eigenvalue problem is formulated. Hence, the concept of self-equilibrating end-effects permits the production of a basis of suitable modes of warping and in-plane deformation over the arbitrary cross-sectional domain, by combining St. Venant 2-D central solution concept with eigenvalue analysis.

The formulation of advanced beam theories incorporating warping/distortional effects in beams of arbitrary cross-sections has received limited amount of literature. In the majority of the relevant studies, the concepts described in previous paragraph have been used. Exploiting the insight offered by St. Venant solutions, El Fatmi and Ghazouani [66]-[68] employ St. Venant in-plane modes with corresponding warping ones for arbitrary orthotropic crosssections multiplied by independent parameters, in order to take into account their nonuniform distribution along the beam length. The same concept has been applied also by Petrov and Geradin [69] who formulated a theory for curved and pre-twisted beams of arbitrary homogeneous cross-sections, covering geometrically nonlinear range as well. Nevertheless, these formulations include only flexural and axial deformation modes originating from the influence of Poisson's ratio, while torsional distortion is excluded. Thus, it could be stated that these research efforts, study Poisson's ratio effects rather than distortion effects. The concept of eigenvalue analysis has been also exploited in some recent research efforts. More specifically, Ferradi and Cespedes [70] formulate a beam element performing FEM-based eigenvalue analysis concerning the distortional behavior of the cross-section (in-plane problem) and compute warping functions separately by employing an expanded equilibrium scheme based on a previous study of the same authors [71]. A FEM formulation for cross-sectional analysis introducing the concept of zero warping-induced work was presented by Pai [63]. This analysis is employed to study isotropic or anisotropic beams undergoing large deformation. Additionally, a FEM procedure based on a mixed variational formulation for orthotropic beams by developing an eigenvalue cross-sectional problem yielding simultaneously distortional and warping functions of the arbitrarily-shaped cross-section was developed by Genoese et al. [72]. Finally, an advanced beam element in which the so-called sequential equilibrium scheme is employed for the computation of warping and distortional functions 
Table 1. Warping and distortional modes of W250x45 cross-section according to the sequential equilibrium scheme.

\begin{tabular}{|c|c|c|c|}
\hline \multicolumn{2}{|c|}{ Warping modes } & \multicolumn{2}{|c|}{ Distortional modes } \\
\hline $\begin{array}{c}1^{\text {st }} \text { sequential equilibrium } \\
\text { stage }\end{array}$ & $\begin{array}{c}2^{\text {nd }} \text { sequential equilibrium } \\
\text { stage }\end{array}$ & $\begin{array}{c}1^{\text {st }} \text { sequential } \\
\text { equilibrium } \\
\text { stage }\end{array}$ & $\begin{array}{c}2^{\text {nd }} \text { sequential } \\
\text { equilibrium } \\
\text { stage }\end{array}$ \\
\hline \multicolumn{4}{|c|}{ Axial modes } \\
\hline & & $=$ & Fine \\
\hline & & $=1$ & \\
\hline
\end{tabular}

Flexural modes for flexure about stong axis

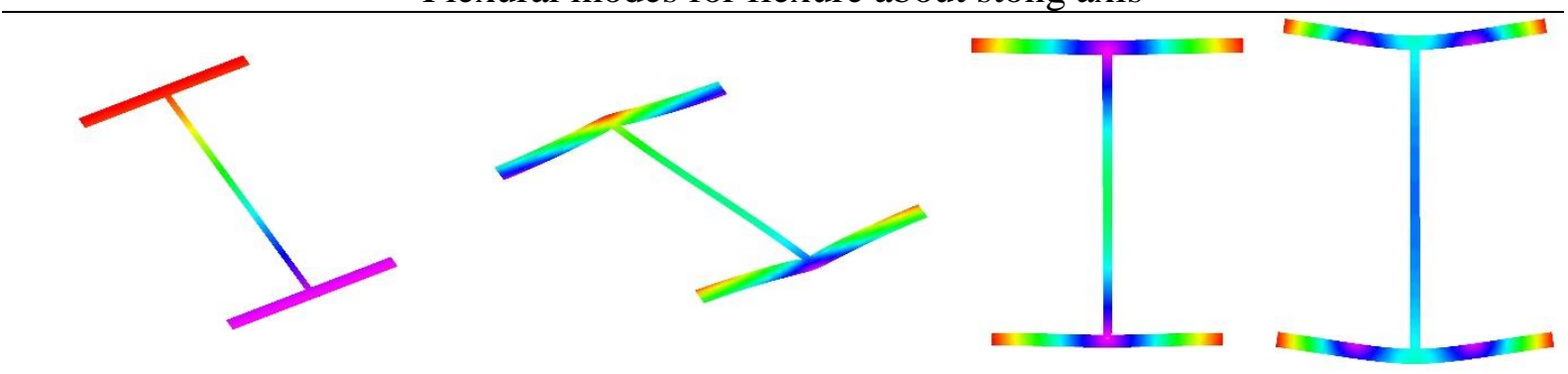

Flexural modes for flexure about week axis

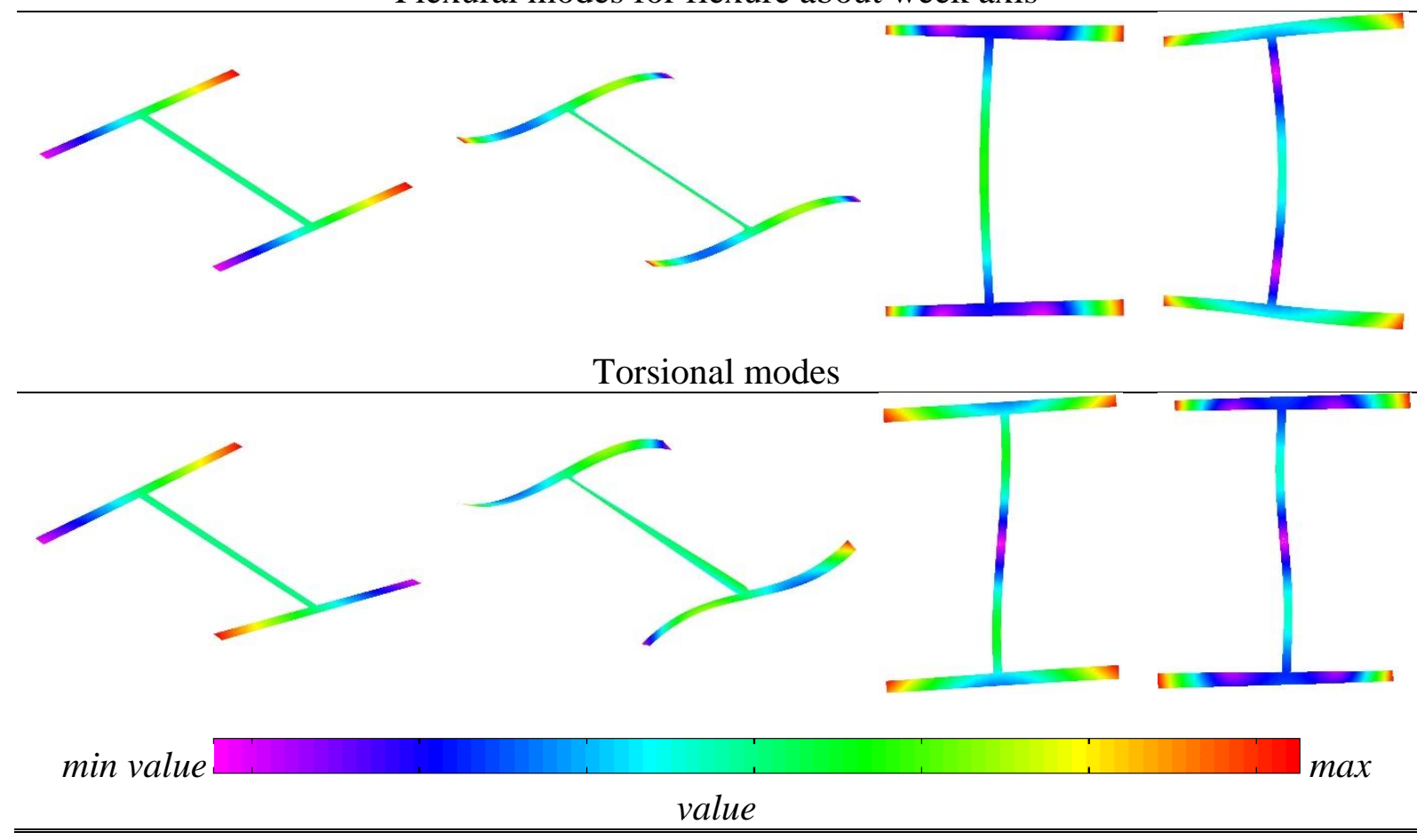

was developed by Dikaros and Sapountzakis [73]. The advantages of this approach over the eigenvalue analysis one are that distortional and warping functions are evaluated by the same problem and in order of significance, while contrary to eigenvalue analysis, it permits the 
separate evaluation of axial, flexural and torsional mode groups. Furthermore, in this way, a beam formulation is developed employing a relatively small number of unknown functions by employing the most "significant" modes (first solutions of the sequential equilibrium scheme) in order to keep the simplicity of the formulation to the highest possible level.

Undoubtedly axial mode is crucial for buckling (and generally non-linear) analysis. As a result research efforts concerning higher order beam theories incorporating axial warping (outof-plane deformation) and axial distortional (in-plane deformation) modes are noteworthy. More specifically, a theory for curved and twisted beams where an axial distortional mode is included was developed by Petrov and Géradin [69]. A higher order composite beam theory built on Saint-Venant's solution taking into account an axial distortional mode was developed by El Fatmiand Ghazouani [68],[74]. Warping and distortional modes solving eigenvalue problems in the context of the Generalized Beam Theory (GBT) were calculated by Jönsson and Andreassen [45] as well as Ranzi and Luongo [44]. Thin-walled straight beams with generally shaped closed sections using numerically determined sectional deformation functions (warping and distortional modes are obtained through an eigenvalue problem) were analyzed by Jang et al. [76]. Elastic buckling of uniformly compressed thin-walled regular polygonal tubes in the concept of GBT, including axial warping and distortional modes was studied by Gonçalves and Camotim [78]. A generalized model for heterogeneous and anisotropic beams including section distortions, integrating axial warping and distortional modes for both thinand thick- walled cross-sections through the solution of an eigenvalue problem was presented by Genoese et al. [72]. An advanced beam element under longitudinal external loading by BEM where the first axial warping mode is evaluated with respect to external loading was presented by Sapountzakis et. al. [79]. Finally, a model reduction technique for beam analysis with the asymptotic expansion method where the warping and distortional deformation modes are determined in function of the applied loads and the limit conditions of the problem, was developed by Ferradi et al. [80].

However, the majority of the aforementioned beam theories have limitations regarding the cross-sectional shape or the loading. In more detail, only the first axial distortional mode is employed in [68],[69],[74], only the first axial warping mode is employed in [79], while assumptions of thin-walled beam theory are adopted in [44],[45],[76],[78]. In addition, warping functions are calculated in function of applied loads and limit conditions, requiring a new crosssectional analysis for each loading or limit condition, in [80], which is not the concept of a higher order beam theory. Moreover, although the cross-section can be thin- or thick- walled and assumptions of thin walled beam theory are not adopted in [72], axial modes are calculated through the solution of an eigenvalue problem. Finally, Argyridi and Sapountzakis [81] developed a higher order beam theory for generally loaded beams of arbitrary cross-section where axial warping and distortional modes are evaluated employing the concept of sequential equilibrium scheme. In order to exemplify the axial warping and distortional modes of [81] and taking into account that in [81] these modes of a hollow rectangular cross section (closed crosssection) are illustrated, in table 1 warping and distortional modes of W250x45 cross-section (open cross-section) are presented according to the sequential equilibrium scheme [81]. In contrast, in the numerical example of Section 4, the linear buckling of a hollow rectangular cross section, which hasn't been examined in [82], is examined as a comparison with literature.

\section{Buckling analysis by means of higher order beam theories considering warping and distortion}

Unquestionably, elastic stability of beams is one of the most important criteria in the design of structures (e.g. [83]). In addition, in stability problems members vulnerable to out-of-plane and/or in-plane deformations are more likely to develop such deformations by means of local 
buckling. Numerous of scientists have been concerned with this issue. Chen and co-workers [84] were the first that included a simple analytical model in their beam formulation to account for the effects of local buckling of circular cross-section. Since then a lot of research efforts have been dealt with buckling including shear lag and distortional effects in the concept of a beam theory. A group of researchers have studied local buckling of beams employing GBT. GBT was used by Davies and coworkers to investigate the buckling of cold-formed steel (opensection) profiles [85], while GBT was employed by Camotim and co-workers to study local buckling of beams regarding steel and aluminum columns [32], thin-walled regular polygon tubes, angle, T-sections and cruciform thin-walled members [36],[78],[87], cold formed steel purlins[88], steel-concrete composite beams [75], generally loaded thin-walled members with arbitrary flat-walled cross-sections [86]. Another group of researchers, examined buckling of beams by means of Finite Strip Method (FSM) [53],[54],[89] that relies on plate theory assumptions which are applied on each wall of the cross-section. A model that accounts for global behavior and for local buckling as well was formulated by Karamanos and co-workers. The global (beam-type) response is described through Lagrange polynomials and the crosssectional ovalization/warping in terms of trigonometric functions. This formulation has succeeded in simulating local buckling in circular hollow section members [90-93]. Local buckling has also been examined for several cases of thin walled sections [e.g. 94-97]. Nevertheless, all the aforementioned researches deal with the problem of local buckling employing assumptions of TTT and in some cases and the applicability of their methods depends on the cross-sectional shape. To overcome these disadvantages, Argyridi and Sapountzakis [82] developed a higher order beam theory for the buckling analysis of arbitrarily shaped beams where warping and distortional modes (axial additionally to flexural and torsional ones) are evaluated employing the concept of sequential equilibrium scheme. This higher order beam theory is employed in the present paper to examine the influence of distortion in the response of beams evaluated by higher order beam theories. In addition, comparisons with models of Euler -Bernoulli, Timoshenko beam theories, and $3 \mathrm{~d}$ Solid finite elements are conducted to highlight the influence of the phenomenon under examination.

\section{$4 \quad$ Numerical example}

In order to investigate the influence of distortional phenomenon in the response of beams evaluated by higher order beam theories a numerical example drawn from the literature $[98,99]$ is examined dealing with linear buckling analysis of beams. Closed cross-section cantilever beams (Figure 1a), for length varying from $L=5.0 \mathrm{~m}$ to $L=40.0 \mathrm{~m}$, with a homogeneous ( $E=10^{6} \mathrm{kN} / \mathrm{m}^{2}, v=0.25$ ) rectangular cross-section (Figure $1 \mathrm{~b}$ ) have been analyzed. More specifically, the buckling load has been calculated employing the Higher Order Beam Theory of [82] for varying number of degrees of freedom of each node $\left(N_{\text {dofs }}\right)$ with $40 \mathrm{FE}$ and is compared with the corresponding results according to Generalized Warping Beam Theory (GWBT) with 41 FE (takes into account shear lag both due to flexure and torsion, distortion is not taken into account) [98], Euler - Bernoulli Beam Theory including primary torsional warping (E/BBT) employing 41 FE [98], Timoshenko Beam Theory taking into account primary torsional warping (TBT) employing 50 FE [98], Solid FEM without diaphragms (w/out d.) [98] and solid FEM with diaphragms (with d.) [98]. In this example, in the Solid FEM with d. model rigid diaphragms in each set of nodes having the same longitudinal coordinate have been employed, pointing out that the diaphragms are designed so as each set 


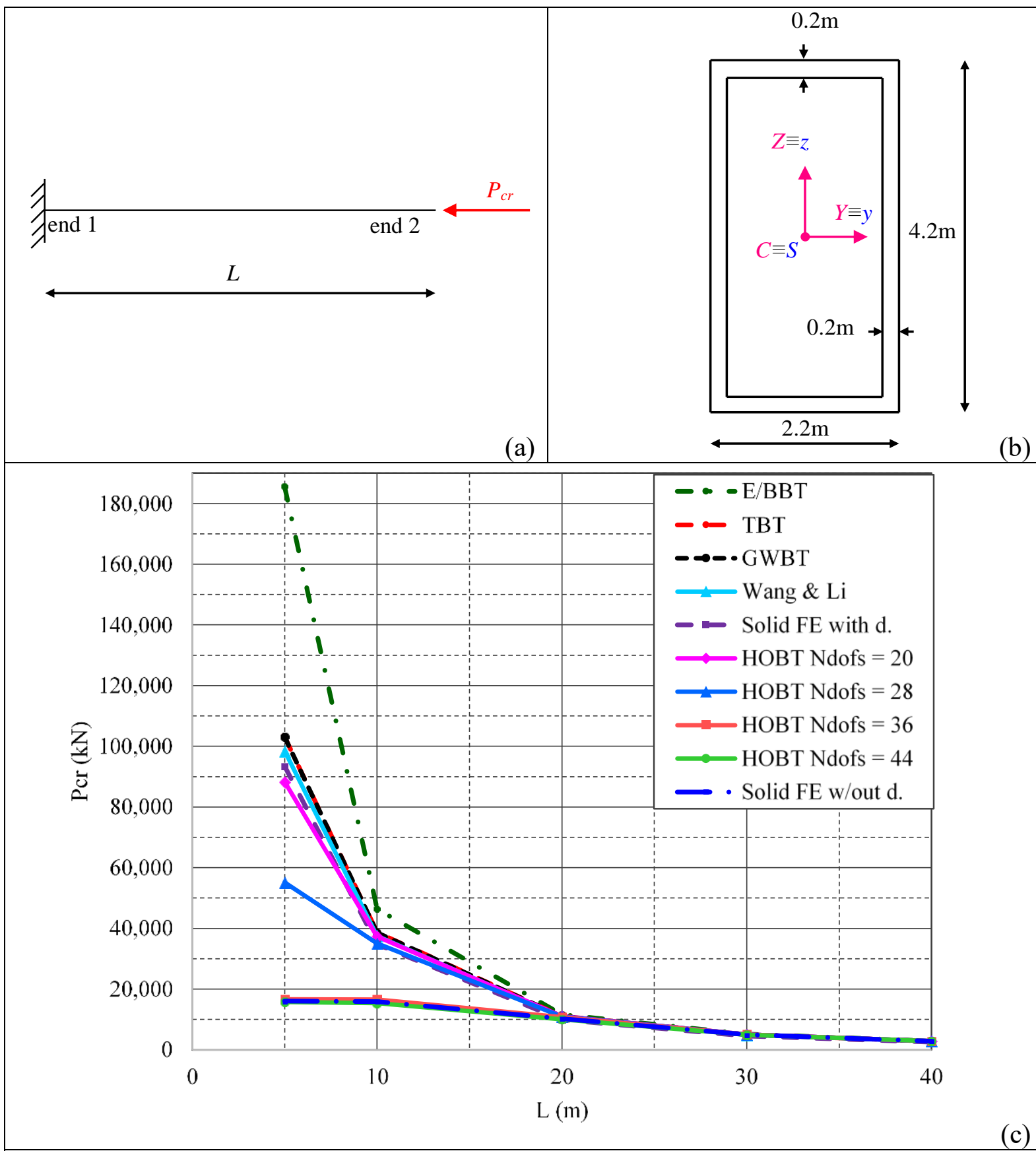

Figure 1: Boundary conditions and loading (a), cross section (b) and buckling loads of beams of numerical example as obtained from E/BBT [98], TBT[98], GWBT [98], Solid FEM with and without diaphragms [98], Wang and Li [99] and HOBT of [82]] for various Ndofs(c).

of nodes has the same translation and rotation in the cross-section plane, corresponding to that cross-section maintains its shape at the transverse directions during deformation (distortion is not taken into account -assumption of E/EBT, TBT, GWBT). In both solid FEM models 1200 solid FE per meter of length have been employed [98]. The aforementioned results are compared with those calculated by Wang and $\mathrm{Li}$ [99] which calculated the buckling loads of thin walled members taking into account shear lag effect (distortion is not taken into account). Figure 1c shows the aforementioned buckling loads. 
The discrepancies between Solid FEM with d. and Solid FEM w/out d. as well as those between GWBT and HOBT for $N_{\text {dofs }}=36$ show that for the lengths where the two solutions are different local buckling is dominant. Comparing HOBT results with those obtained by Solid FEM w/out d. it is obvious that as the $N_{\text {dofs }}$ increases HOBT results approach Solid FEM w/out d. solution. Especially for $N_{\text {dofs }}$ equal to 36 and 44 the results are almost the same, so can be concluded that HOBT (proposed method) convergences and that for sufficient $N_{\text {dofs }}$ HOBT can give as accurate results as Solid FEM w/out d. even in cases of short lengths (e.g. Beam Length longest side of the cross section $=1.19$ for $L=5 m$ ) where local buckling dominates (Figure 2a,b). The buckling load calculated from HOBT for $N_{\text {dofs }}=36$, solid FEM w/out d. and solid FEM with d. for $L=5 m$ is $\mathrm{P}_{c r}^{\text {HOBT }}=16,672.62 \mathrm{kN}, \quad \mathrm{P}_{c r}^{\text {Solid FEM wloutd. }}=16,030.75 \mathrm{kN} \quad$ and $\mathrm{P}_{c r}^{\text {Solid FEM with d. }}=93,440.91 \mathrm{kN}$ respectively. So it holds that $\frac{\mathrm{P}_{c r}^{\text {HOBT }}-\mathrm{P}_{c r}^{\text {Solid FEM wout d. }}}{\mathrm{P}_{c r}^{\text {Solid FEM w/out d. }}}=4 \%$ and $\frac{\mathrm{P}_{c r}^{\text {Solid FEM with d. }}-\mathrm{P}_{c r}^{\text {Solid FEM w/out d. }}}{\mathrm{P}_{c r}^{\text {Solid FEM wloutd. }}}=482 \%$. From these comparisons the great importance of the
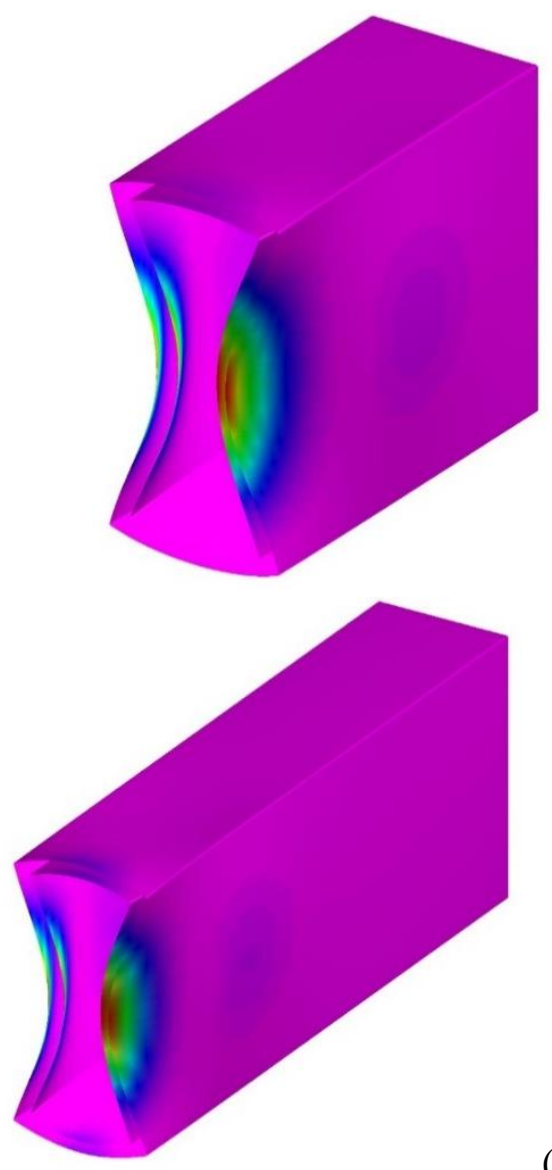

(c)

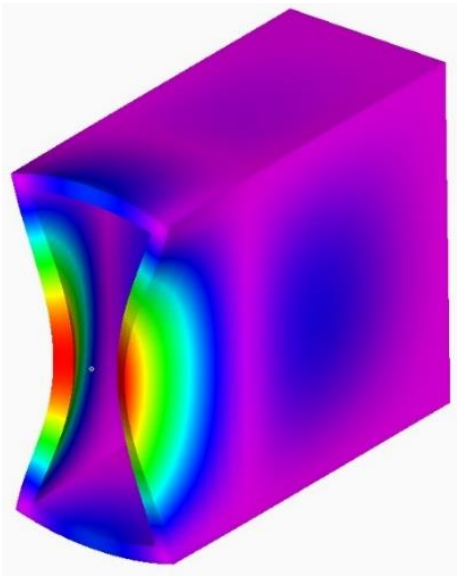

(b)

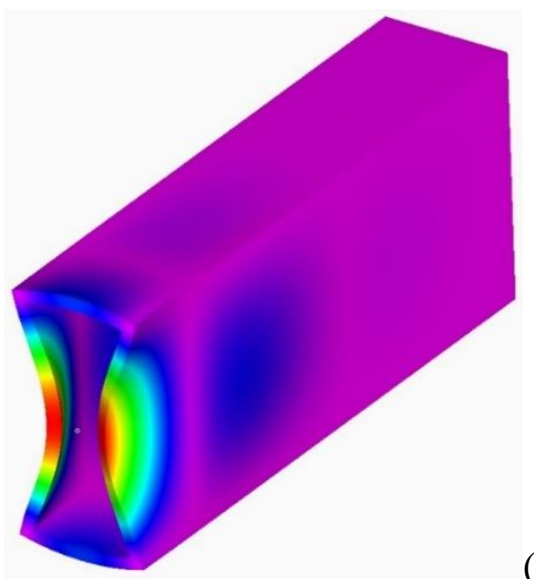

(d)

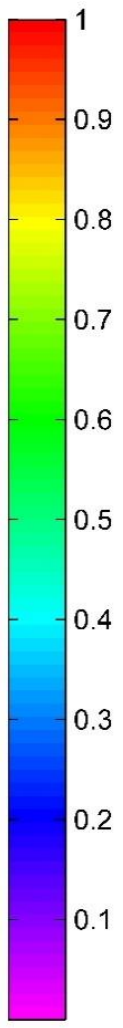

Figure 2: Modeshape for $L=5 m(\mathrm{a}, \mathrm{b})$ and $L=10 \mathrm{~m}$ (c, d) as calculated by HOBT of [82] for $N_{\text {dofs }}=36$ and Solid FEM without diaphragms, respectively. 


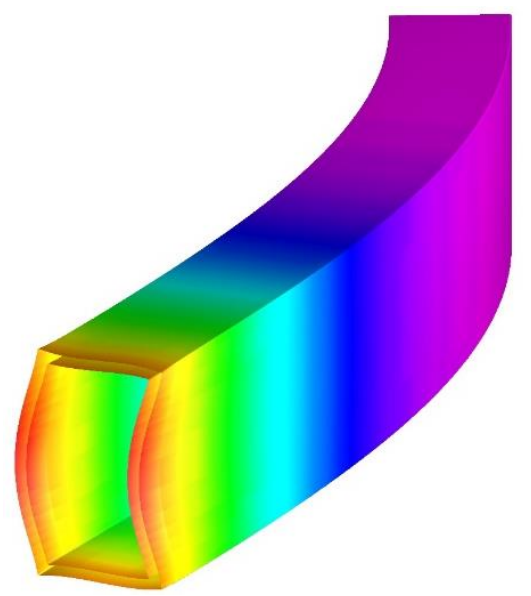

(a)
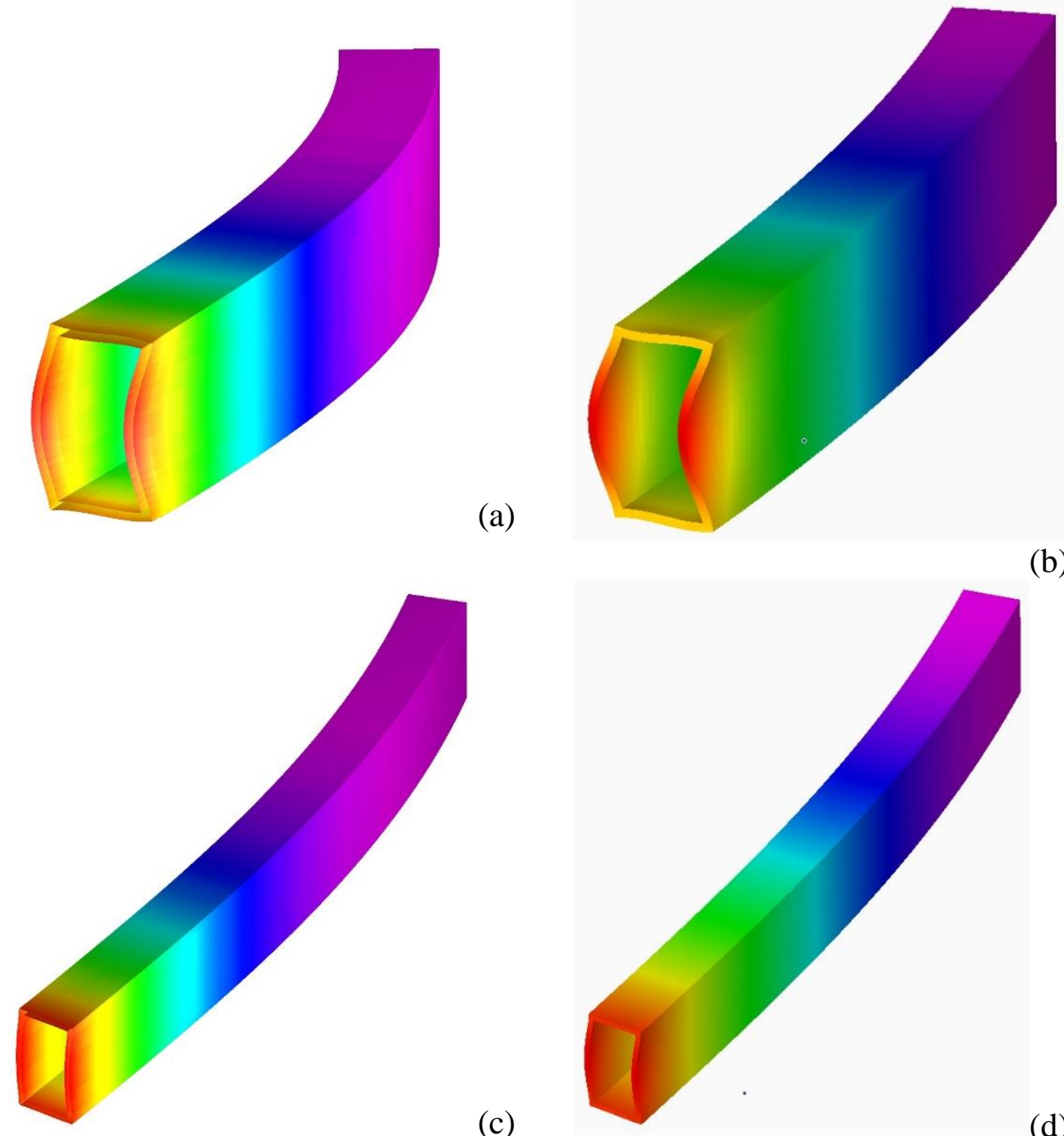

(b)

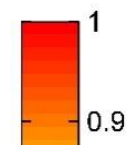

(c)
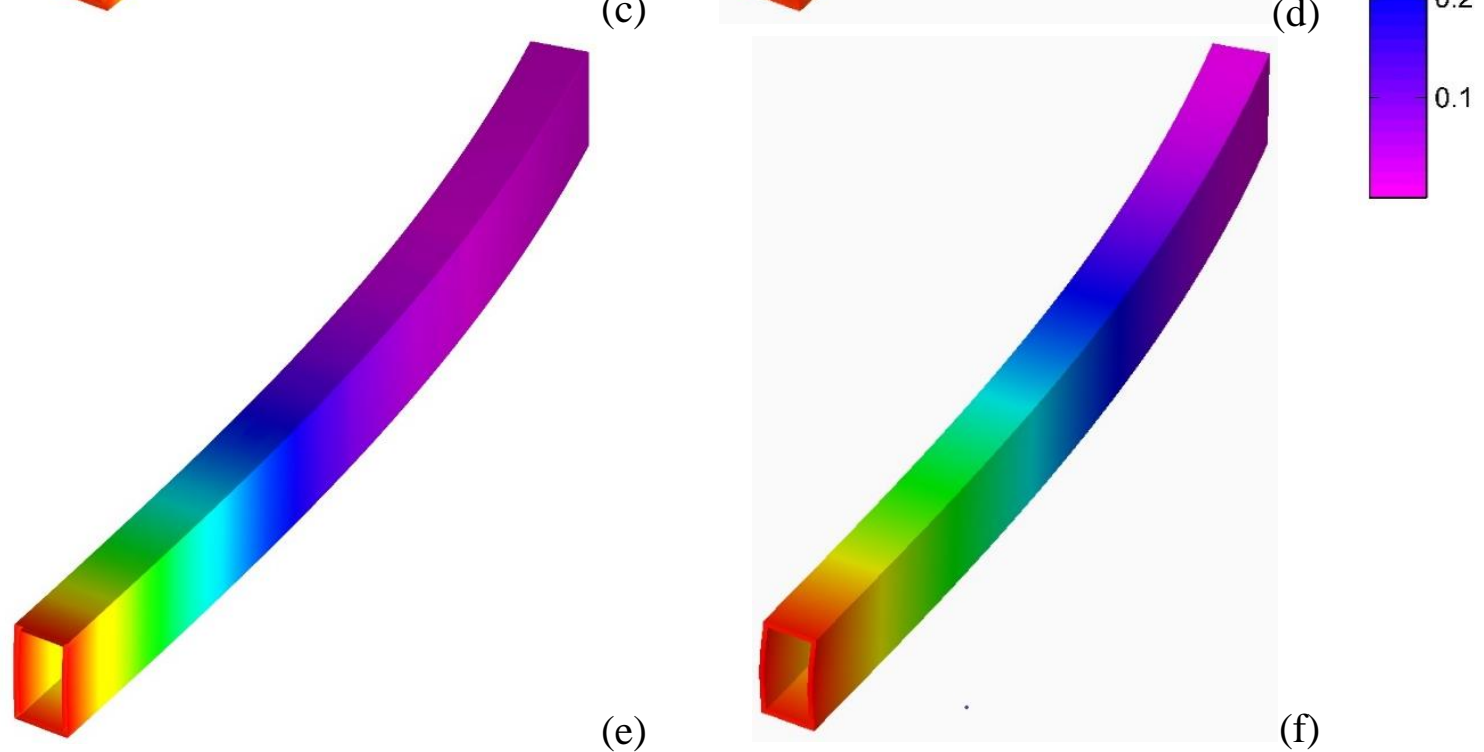

(e)

(f)

Figure 3: Modeshape for $L=20 \mathrm{~m}$ (a, b), $L=30 \mathrm{~m}$ (c, d) and $L=40 m(\mathrm{e}, \mathrm{f})$ as calculated by HOBT of [82] for $N_{\text {dofs }}=36$ and Solid FEM without diaphragms, respectively. 
distortional phenomenon in buckling analysis of beams is apparent. In addition, it is concluded that distortional phenomenon is much more important than warping phenomenon.

Figure 2 presents the buckling modeshapes for $L=5 \mathrm{~m}$ (Figure 2a,b) and $L=10 \mathrm{~m}$ (Figure $2 \mathrm{c}, \mathrm{d}$ ) as calculated by HOBT for $N_{\text {dofs }}=36$ and Solid FEM without diaphragms, respectively. It is obvious that these modeshapes correspond to local buckling which is consistent to the fact that the buckling loads of GWBT and HOBT for $N_{d o f s}=36$ are not the same. Comparing HOBT with solid FEM w/out d. results can be concluded that the respective modeshapes are identical, as expected.

Figure 3 presents the buckling modeshapes for $L=20 \mathrm{~m}$ (Figure $3 \mathrm{a}, \mathrm{b}$ ), $L=30 \mathrm{~m}$ (Figure $3 \mathrm{c}, \mathrm{d}$ ) and $L=40 \mathrm{~m}$ (Figure $3 \mathrm{e}, \mathrm{f}$ ) as calculated by HOBT for $N_{\text {dofs }}=36$ and Solid FEM without diaphragms, respectively. It is obvious that these modeshapes correspond to global buckling, which is consistent with the fact that the buckling loads of GWBT and HOBT for $N_{\text {dofs }}=36$ are approximately the same. Comparing HOBT with solid FEM w/out d. results can be concluded that the respective modeshapes are identical.

\section{CONCLUSION}

In this paper, after briefly overviewing literature of the major beam theories taking account warping and distortional deformation, the influence of distortion in the response of beams evaluated by higher order beam theories is examined via a numerical example of buckling drawn from the literature. Analysis of members by means of a beam theory consists of two steps. In the first step, the geometric constants of the beam cross-section are evaluated via a cross-sectional analysis. In the second step, the global equilibrium equations of the beam, using the evaluated geometric constants, are solved to calculate the response of the loaded member. The way of calculation of cross-sectional characteristics is depicted as the essential reason that differentiates currently existing beam theories. In addition, the numerical investigation of the influence of distortional phenomenon in the response of beams evaluated by higher order beam theories leads to the following conclusions:

- Distortional phenomenon has great influence in the calculation of the linear buckling load.

- As far as the evaluation of beams buckling load is concerned, distortional phenomenon is much more important than warping phenomenon.

- The employed higher order beam theory is able to accurately evaluate the buckling load of beams even in cases of very short lengths. In cases of such members, $3 \mathrm{~d}$ theory of elasticity could be considered as more appropriate than a higher order beam theory.

\section{ACKNOWLEDGMENTS}

A. K. Argyridi would like to express her sincere thanks to the Onassis Foundation - Vaduz, Principality of Liechtenstein - Scholarship ID: G ZK 005-1/2014-2015, Foundation for Education and European Culture - Greece, and the A. G. Leventis Foundation - Vaduz, Principality of Liechtenstein for their support during her PhD studies.

\section{REFERENCES}

[1] J. Murin, M. Aminbaghai, V. Goga, V. Kutiš , J. Paulech 1, J. Hrabovský. Effect of nonuniform torsion on elastostatics of a frame of hollow rectangular cross-section. Journal of Mechanical Engineering - Strojnícky časopis 2018 (68), No. 2, 35 - 52. 
[2] R. Schardt. Lateral torsional, and distortional buckling of channel-, and hat-sections. Journal of Constructional Steel Research 1994 (31), No. 2 - 3, 243 - 265.

[3] E. Reissner. Analysis of shear lag in box beams by the principle of minimum potential energy. Quarterly of Applied Mathematics 1946 (4), No. 3, 268 - 278.

[4] D. J. Malcolm, R.G. Redwood. Shear lag in stiffened box-girders. J. Struct. Div. ASCE 1970 (96), No. 7, $1403-1415$.

[5] K. R. Moffatt, P. J. Dowling. Shear lag in steel box-girder bridges. Struct. Engineer 1975 (53), No. 10, $439-448$.

[6] N.W. Murray. Introduction to the theory of thin-walled structures. Oxford University Press, 1986.

[7] Eurocode 3: Design of Steel Structures - Part 1.5: Plated Structural Elements, European Committee for Standardization, 2004, prEN 1993-1-5.

[8] Eurocode 4: Design of Composite Steel and Concrete Structures - Part 1.1: General Rules and Rules for Buildings, European Committee for Standardization, 2004, prEN 1994-11 .

[9] Eurocode 4: Design of Composite Steel and Concrete Structures - Part 2: General Rules and Rules for Bridges, European Committee for Standardization, 2004, prEN 1994-2.

[10] Eurocode 2: Design of concrete structures - Part 2: Concrete bridges - Design and detailing rules, European Committee for Standardization, 2005, EN 1992-2.

[11] C. A., Ie, J. B. Kosmatka. On the analysis of prismatic beams using first-order warping functions. International Journal of Solids, and Structures 1992 (29), No. 7, 879 - 891.

[12] Eurocode 9: Design of aluminium structures - Part 1.3: Structures susceptible to fatigue, European Committee for Standardization, 2007, EN 1999-1-3.

[13] N.H., Park, N.H., Lim, Y.J. Kang. A consideration on intermediate diaphragm spacing in steel box girder bridges with a doubly symmetric section. Engineering Structures $\mathbf{2 0 0 3}$ (25), No. 13, $1665-1674$.

[14] V. Vlasov. Thin-walled elastic beams. Israel Program for Scientific Translations, Jerusalem, 1963.

[15] R.N. Wright, S.R. Abdel-Samad, A.R. Robinson. BEF analogy for analysis of box girders. J. Struct. Div., ASCE 1968 (94), No. 7, 1719 - 1743.

[16] L.T. Stavridis. Structural Systems: Behaviour, and design. Thomas Telford Limited, 40 Marsh Wall, London, 2010.

[17] L.F. Boswell, S.H. Zhang. A box beam finite element for the elastic analysis of thinwalled structures. Thin-Walled Structures 1983 (1), No. 4, 353 - 383.

[18] L.F. Boswell, S.H. Zhang. The effect of distortion in thin-walled box-spine beams. International Journal of Solids and Structures 1984 (20), No. 9 - 10, 842 - 862.

[19] S.H. Zhang, L.P.R. Lyons. A thin-walled box beam finite element for curved bridge analysis. Computers and Structures 1984 (18), No. 6, 1035 - 1046.

[20] S.H. Zhang, L.P.R. Lyons. The application of the thin-walled box beam element to multibox bridge analysis. Computers and Structures 1984 (18), No. 5, 795 - 802.

[21] B. Kermani, P. Waldron. Analysis of continuous box girder bridges including the effects of distortion. Computers and Structures 1993 (47), No. 3, 427 - 440. 
[22] N.I. Kim, M.Y. Kim. Exact dynamic/static stiffness matrices of non-symmetric thinwalled beams considering coupled shear deformation effects. Thin-Walled Structures 2005 (43), No. 5, $701-734$.

[23] N.H. Park, S. Choi, Y.J. Kang. Exact distortional behavior, and practical distortional analysis of multicell box girders using an expanded method. Computers and Structures 2005 (83), No. 19 - 20, 1607 - 1626.

[24] L.F. Boswell, Q. Li. Consideration of the relationships between torsion, distortion, and warping of thin-walled beams. Thin-Walled Structures 1995 (21), No. 2, 147 - 161.

[25] R. Schardt. Verallgemeinerte technicsche biegetheory. Germany: Springler - Verlag, 1989.

[26] R. Schardt. Generalised Beam Theory - An adequate method for coupled stability problems. Thin-Walled Structures 1994 (19), No. 2 - 4, 161 - 180.

[27] J.M. Davies, P. Leach. First-order Generalized Beam Theory. Journal of Constructional Steel Research 1994 (31), No. 2 - 3, 187 - 221.

[28] J.M. Davies, P. Leach, D. Heinz. Second-order Generalized Beam Theory. Journal of Constructional Steel Research 1994 (31), No. 2 - 3, 221 - 241.

[29] P. Leach. The calculation of modal cross-section properties for use in the Generalized Beam Theory. Thin-Walled Structures 1994 (19), No. 1, 61 - 79.

[30] P. Leach, J. M. Davies. An experimental verification of the Generalized Beam Theory applied to interactive buckling problems. Thin-Walled Structures 1996 (25), No. 1, 61 79.

[31] N. Silvestre, D. Camotim. First-order Generalised Beam Theory for arbitrary orthotropic materials. Thin-Walled Structures 2002 (40), No. 9, 755 - 789.

[32] R. Gonçalves, D. Camotim. GBT local, and global buckling analysis of aluminium, and stainless steel columns. Computers and Structures 2004 (82), No. 17 - 19, 1473 - 1484.

[33] R. Gonçalves, D. Camotim. Thin-walled member plastic bifurcation analysis using Generalised Beam Theory. Advances in Engineering Software 2007 (38), No. 8 - 9, 637 -646 .

[34] R. Gonçalves, D. Camotim. Generalised Beam Theory-based finite elements for elastoplastic thin-walled metal members. Thin-Walled Structures 2011 (49), No. 10, 1237 $-1245$.

[35] N. Silvestre. Generalised Beam Theory to analyse the buckling behaviour of circular cylindrical shells, and Tubes. Thin-Walled Structures 2007 (45), No. 2, 185 - 198.

[36] P. B. Dinis, D. Camotim, N. Silvestre. On the local, and global buckling behaviour of angle, t-section, and cruciform thin-walled members. Thin-Walled Structures 2010 (48), No. $10-11,786-797$.

[37] R. Gonçalves, M. R. Corrêa, D. Camotim. A large displacement, and finite rotation thinwalled beam formulation including cross-section deformation. Comput. Methods Appl. Mech. Engrg 2010 (199), No. 23 - 24, 1627 - 1643.

[38] N. Silvestre, D. Camotim. On the mechanics of distortion in thin-walled open sections. Thin-Walled Structures. 2010 (48), No. 7, 469 - 481.

[39] D. Camotim, P. B. Dinis. Coupled instabilities with distortional buckling in cold-formed steel lipped channel columns. Thin-Walled Structures 2011 (49), No. 5, 562 - 575. 
[40] P.B. Dinis, D. Camotim. Post-buckling behaviour, and strength of cold-formed steel lipped channel columns experiencing distortional/global interaction. Computers and Structures 2011 (89), No. 3 - 4, 422 - 434.

[41] M. Abambres, D. Camotim, N. Silvestre. GBT-Based first-order analysis of elastic plastic thin-walled steel members exhibiting strain-hardening. The IES Journal Part A: Civil, and Structural Engineering 2013 (6), No. 2., 119 - 134. DOI: 10.1080/19373260. 2012.757209

[42] C. D. Balch, C. R. Steele. Asymptotic solutions for warping, and distortion of thin-walled box beams. Journal of Applied Mechanics, ASME 1987 (54), No. 1, 165 - 173.

[43] L. Mentrasti. Distorion (and torsion) of rectangular thin-walled beams. Thin-Walled Structures 1990 (10), No. 3, 175 - 193.

[44] G. Ranzi, A. Luongo. A new approach for thin-walled member analysis in the framework of GBT, Thin-Walled Structures 2011 (49), No. 11, 1404 - 1414.

[45] J. Jönsson, M. J. Andreassen. Distortional eigenmodes, and homogeneous solutions for semi-discretized thin-walled beams. Thin-Walled Structures 2011 (49), No. 6, 691 - 707.

[46] M. J. Andreassen, J. Jönsson. Distortional solutions for loaded semi-discretized thinwalled beams. Thin-Walled Structures 2012 (50), No. 1, 116 - 127.

[47] M. J. Andreassen, J. Jönsson. Distortional buckling modes of semi-discretized thinwalled columns. Thin-Walled Structures 2012 (51), 53 - 63.

[48] M. J. Andreassen, J. Jönsson. A distortional semi-discretized thin-walled beam element. Thin-Walled Structures 2013 (62), 142 - 157.

[49] R. F. Vieira, F. B. Virtuoso, E. B. R. Pereira. A higher order model for thin-walled structures with deformable cross-sections. International Journal of Solids and Structures 2014 (51), No. 3 - 4, 575 - 598.

[50] B. W. Schafer, S. Ádány. Understanding, and classifying local, distortional, and global buckling in open thin-walled members. Annual Conference Structural Stability Research Council, Montreal, Canada, 2005.

[51] D. Camotim, N. Silvestre, R. Gonçalves, P. B. Dinis. GBT-based structural analysis of thin-walled members: overview, recent progress and future developments. M. Pandey et al. (eds), Advances in Engineering Structures, Mechanics \& Construction 2006 (140), $187-204$.

[52] B. W. Schafer, S. Ádány. Buckling analysis of cold-formed steel members using CUFSM: conventional, and constrained Finite Strip Methods. 18th International Specialty Conference on Cold-Formed Steel Structures, Orlando, Florida, 2006.

[53] S. Ádány, B. W. Schafer. Buckling mode decomposition of single-branched open crosssection members via Finite Strip Method: Derivation. Thin-Walled Structures, 2006 (44), No. $5,563-584$.

[54] S. Ádány, B. W. Schafer. Buckling mode decomposition of single-branched open crosssection members via Finite Strip Method: Application, and examples. Thin-Walled Structures 2006 (44), No. 5, 585 - 600.

[55] S. Ádány, B. W. Schafer. A full modal decomposition of thin-walled, single-branched open cross-section members via the constrained Finite Strip Method. Journal of Constructional Steel Research 2008 (64), No. 1, 12 - 29. 
[56] Z. Li, M.T. Hanna, S. Ádány, B. W. Schafer. Impact of basis, orthogonalization, and normalization on the constrained Finite Strip Method for stability solutions of open thinwalled members. Thin-Walled Structures 2011 (49), No. (9), 1108 - 1122.

[57] V. J. Tsipiras, E. J. Sapountzakis. Bars under nonuniform torsion - application to steel bars, Assessment of EC3 guidelines. Engineering Structures 2014 (60), 133 - 147.

[58] J. B. Kosmatka, S. B. Dong. Saint-Venant solutions for prismatic anisotropic beams. International Journal of Solids and Structures 1991 (28), No. 7, 917 - 938.

[59] C.A. Ie, J. B. Kosmatka. Saint-Venant elasticity solutions of a tip-loaded anisotropic cantilevered beam with an elliptical section. Composites Engineering 1993 (3), No. 12, $1149-1164$.

[60] A. E. H. Love. A treatise on the mathematical theory of elasticity, Dover, New York, 1944.

[61] X. S. Xu, W. X. Zhong. H. W. Zhang. The Saint-Venant problem, and principle in elasticity. International Journal of Solids and Structures 1997 (34), No. 22, 2815 - 2827.

[62] S. W. Reagan, W. D. Pilkey. Constrained torsion of prismatic bars. Finite Elements in Analysis, and Design 2002 (38), No. 10, 909 - 919.

[63] P. F. Pai. High-fidelity sectional analysis of warping functions, stiffness values, and wave properties of beams. Engineering Structures 2014 (67), No. 15, 77 - 95.

[64] V. Giavotto, M. Borri, P. Mantegazza, G. Ghiringhelli, V. Carmaschi, G. C. Maffioli, F. Mussi. Anisotropic beam theory, and applications. Computers and Structures 1983 (16), No. $1-4,403-413$.

[65] M. Kazic, S. B. Dong. Analysis of restrained torsion. Journal of Engineering Mechanics, 1990 (116), No. 4, 870 - 891.

[66] N. Ghazouani, R. El Fatmi. Extension of the non-uniform warping theory to an orthotropic composite beam. Comptes Rendus Mecanique 2010 (338), No. 12, 704 - 711.

[67] N. Ghazouani, R. El Fatmi. Higher order composite beam theory built on Saint-Venant's Solution. Part-II: Built-in effects influence on the behavior of end-loaded cantilever beams. Composite Structures 2011 (93), No. 2, 567 - 581.

[68] R. El Fatmi, N. Ghazouani. Higher order composite beam theory built on Saint-Venant's Solution. Part-I: Theoretical developments. Composite Structures 2011 (93), No. 2, 557 $-566$.

[69] E. Petrov, M. Géradin. Finite element theory for curved, and twisted beams based on exact solutions for three-dimensional solids, Part 1: Beam concept, and geometrically exact nonlinear formulation. Computational Methods in Applied Mechanics, and Engineering. 1998 (165), No. 1 - 4, 43 - 92.

[70] M. K. Ferradi, X. Cespedes. A new beam element with transversal, and warping eigenmodes. Computers and Structures 2014 (131), 12 - 33.

[71] M. K. Ferradi, X. Cespedes, M. Arquier. A higher order beam finite element with warping eigenmodes. Engineering Structures 2013 (46), 748 - 762.

[72] A. Genoese, A. Genoese, A. Bilotta, G. Garcea. A generalized model for heterogeneous, and anisotropic beams including section distortions. Thin-Walled Structures 2014 (74), $85-103$. 
[73] I. C. Dikaros, E. J. Sapountzakis. Distortional analysis of beams of arbitrary cross section by BEM. Journal of Engineering Mechanics, ASCE 2017 (143), No. 10, 04017118, DOI:10.1061/(ASCE)EM.1943-7889.0001340

[74] N. Ghazouani, R. El Fatmi. Higher order composite beam theory built on Saint-Venant's solution, Part-II: Built-in effects influence on the behavior of end-loaded cantilever beams. Composite Structures 2011 (93), No. 2, 567 - 581.

[75] D. Henriques, R. Gonçalves, D. Camotim. GBT-based finite element to assess the buckling behaviour of steel-concrete composite beams. Thin-Walled Structures 2016, (107), $207-220$.

[76] G.-W. Jang, M.-J. Kim, Y. Y. Kim. Analysis of thin-walled straight beams with generally shaped closed sections using numerically determined sectional deformation functions. Journal of Structural Engineering, ASCE 2012 (138), No. 12, 1427 - 1435.

[77] E. J. Sapountzakis, V. G. Mokos. Warping shear stresses in nonuniform torsion by BEM. Computational Mechanics 2003 (30), No. 2, 131 - 142.

[78] R. Gonçalves, D. Camotim. Elastic buckling of uniformly compressed thin-walled regular polygonal tubes. Thin-Walled Structures 2013 (71), 35 - 45.

[79] E. Sapountzakis, L. Tsellos, I. Dikaros. Advanced beam element under longitudinal external loading by BEM. Proc. of the 16th International Conference on Boundary Elements, and Meshless Techniques, 2015, 267 - 272, Valencia, Spain, July 06-08.

[80] M. K. Ferradi, A. Lebée, A. Fliscounakis, X. Cespedes, K. Sab. A model reduction technique for beam analysis with the asymptotic expansion method. Computers and Structures 2016, (172), 11 - 28.

[81] A. K. Argyridi, E. J. Sapountzakis. Advanced analysis of arbitrarily shaped axially loaded beams including axial warping and distortion. Thin-Walled Structures 2019 (134), 127 147.

[82] A. K. Argyridi, E .J. Sapountzakis. Higher Order Beam Theory for Linear Local Buckling Analysis. Engineering Structures 2018 (177), 770 - 784.

[83] J. Bocko, P. Lengvarský, J. Šarloši. Buckling analysis of hetero-junction carbon nanotubes. Journal of Mechanical Engineering - Strojnícky časopis 2018, (68), No. 2, 9 -16 .

[84] I. S. Sohal, W. F. Chen. Local, and post-buckling behavior of tubular beam-columns. ASCE Journal of Structural Engineering 1988 (114), No. 5, 1073 - 1090.

[85] J. Davies, P. Leach, D. Heinz. Second-order generalised beam theory. Journal of Constructional Steel Research 1994 (31), No. 2 - 3, 221 - 241.

[86] R. Bebiano, C. Basaglia, D. Camotim, R. Gonçalves. GBT buckling analysis of generally loaded thin-walled members with arbitrary flat-walled cross-sections. Thin-Walled Structures 2018 (123), 11 - 24.

[87] R. Gonçalves, D. Camotim. Buckling behaviour of thin-walled regular polygonal tubes subjected to bending or torsion. Thin-Walled Structures 2013 (73), 185- 197.

[88] C. Basaglia, D. Camotim, R. Goncalves, A. Graca. GBT-based assessment of the buckling behaviour of cold-formed steel purlins restrained by sheeting. Thin-Walled Structures, 2013 (72), $217-229$. 
[89] M. Bradford, R. Johnson. Inelastic buckling of composite bridge girders near internal supports. Proceedings of the Institution of Civil Engineers Part 2-Research, and Theory 1987 (83), 143 - 159.

[90] S. A. Karamanos, J. L. Tassoulas. Tubular members. I: Stability analysis, and preliminary results. Journal of Engineering Mechanics 1996 (122), No. 1, 64 - 71.

[91] S. A. Karamanos, J. L. Tassoulas. Tubular members II: Local buckling, and experimental verification. Journal of Engineering Mechanics 1996 (122), No. 1, 72 - 78.

[92] S. A. Karamanos. Bending instabilities of elastic tubes. International Journal of Solids, and Structures 2002 (39), No. 8, 2059 - 2085.

[93] S. Houliara, S. A. Karamanos. Buckling, and post-buckling of long pressurised elastic thin-walled tubes under in-plane bending. Int. J. Nonlinear Mech. 2006 (41), No. (4), 491 $-511$.

[94] T. Aoki, Y. Migita, Y. Fukumoto. Local buckling strength of closed polygon folded section columns. J Constr Steel Res, 1991 20(4), 259-70.

[95] W. H. Wittrick. A unified approach to the initial buckling of stiffened panels in compression. Aeronautical Quarterly 1968 (19), No. 3, 265 - 283.

[96] C.E. Kurt, R.C. Johnson. Cross sectional imperfections, and columns stability. Journal of the Structural Division, 1978 (104), No. 12, 1869 - 1883.

[97] N. Koseko, T. Aoki, Y. Fukumoto. The local buckling strength of the octagonal section steel columns. Proceedings of the Japan Society of Civil Engineers 1983 (330), 27 - 36.

[98] A.K. Argyridi, E.J. Sapountzakis. Generalized Warping In Flexural-Torsional Buckling Analysis of Composite Beams. Journal of Applied and Computational Mechanics 2016 (2), No. 3, $152-173$.

[99] Q. Wang, W.Y. Li. Buckling of thin-walled compression members with shear lag using spline finite member element method. Computational Mechanics 1996 (18), 139 - 146. 